\title{
Childhood Ovarian Choriocarcinoma
}

National Cancer Institute

\section{Source}

National Cancer Institute. Childhood Ovarian Choriocarcinoma. NCI Thesaurus. Code C6549.

A non-gestational choriocarcinoma that arises from the ovary and occurs in children. 